\title{
Deformation of the Haiyuan-Liupanshan fault zone inferred from the denser GPS observations
}

\author{
Yanchuan Li - Chunyan Qu - Xinjian Shan - Xiaogang Song • \\ Guohong Zhang $\cdot$ Weijun Gan $\cdot$ Shaoyan Wen $\cdot$ Zhenjie Wang
}

Received: 12 July 2015/ Accepted: 23 October 2015/Published online: 17 December 2015

(C) The Author(s) 2015. This article is published with open access at Springerlink.com

\begin{abstract}
The Haiyuan-Liupanshan fault, an active tectonic feature at the Tibetan Plateau's northeastern boundary, was ruptured by two M8 earthquakes (1920 and 1927) bracketing an unbroken section (the Tianzhu seismic gap). A high seismic hazard is expected along the gap. To monitor deformation characteristics and do a seismic risk assessment, we made measurements at two newly built campaign-mode Global Positioning System (GPS) stations and 13 pre-existing stations in 2013 and 2014. Adding existing data from 1999 to 2014, we derived a new velocity field. Based on the horizontal velocity, we used three block models to invert the deformation of four crustal blocks. The results suggest non-uniform deformation in the interior of the Lanzhou block, the Ordos block and the Alaxan block, but uniform deformation in the Qilian block. Fault slip rates derived from block models show a decreasing trend from west to east, $(2.0-3.2 \mathrm{~mm} / \mathrm{a}$ on the Haiyuan fault to $0.9-1.5 \mathrm{~mm} / \mathrm{a}$ on the Liupanshan fault). The Haiyuan fault evidences sinistral striking-slip movement, while the Liupanshan fault is primarily thrusting due to transformation of the displacement between the strike-slip and crustal shortening. The locking depth of each segment along the Haiyuan fault obtained by fitting the fault parallel velocities varies drastically from west to east $(21.8-7.1 \mathrm{~km})$. The moment accumulation rate, calculated
\end{abstract}

\section{Y. Li · Z. Wang}

School of Geosciences, China University of Petroleum (East China), Tsingtao 266580, China

Y. Li · C. Qu · X. Shan $(\bowtie) \cdot$ X. Song · G. Zhang · W. Gan • S. Wen

State Key Laboratory of Earthquake Dynamics, Institute of Geology, China Earthquake Administration, Beijing 100028, China

e-mail: xjshan@163.com using the slip rate and locking depth, is positively correlated with the locking depth. Given the paucity of large seismic events during the previous millennium, the Tuolaishan segment and the Maomaoshan segment have higher likelihood of nucleation for a future event.

Keywords Haiyuan-Liupanshan fault · Block strain model · Fault deformation · GPS

\section{Introduction}

The Haiyuan fault system is part of a major left-lateral fault system in the northeastern margin of the Tibetan Plateau that connects the seismically active Qilian Shan in the west to the tectonically active Liupan Shan in the east, which abuts against the relatively stable Ordos block (Molnar and Tapponnier 1975; Tapponnier and Molnar 1977; Li et al. 2009) (Fig. 1). The fault accommodates part of the deformation induced by the Indian-Asian collision, but no consensus has been reached about the best description of the widespread deformation that occurs there (Cavalié et al. 2008; Thatcher 2007). Neotectonic (Burchfiel et al. 1991; Zhang et al. 1991; Gaudemer et al. 1995; Yuan et al. 1998; Lasserre et al. 1999; He et al. 2000; Tian et al. 2001; Li et al. 2009) and geodetic studies (Meade 2007; Thatcher 2007; Cavalié et al. 2008; Wang et al. 2009; Duvall and Clark 2010; Loveless and Meade 2011; Jolivet et al. 2013; Li et al. 2013) of the Haiyuan fault estimated the Holocene and present-day slip rate, which contributes to a better understanding of the mechanisms of continental deformation and the seismic hazard of the fault. Although the crustal deformation in the northeastern Tibetan Plateau has been studied and characterized, issues still exist, e.g., the fault slip rates obtained by different methods are different 


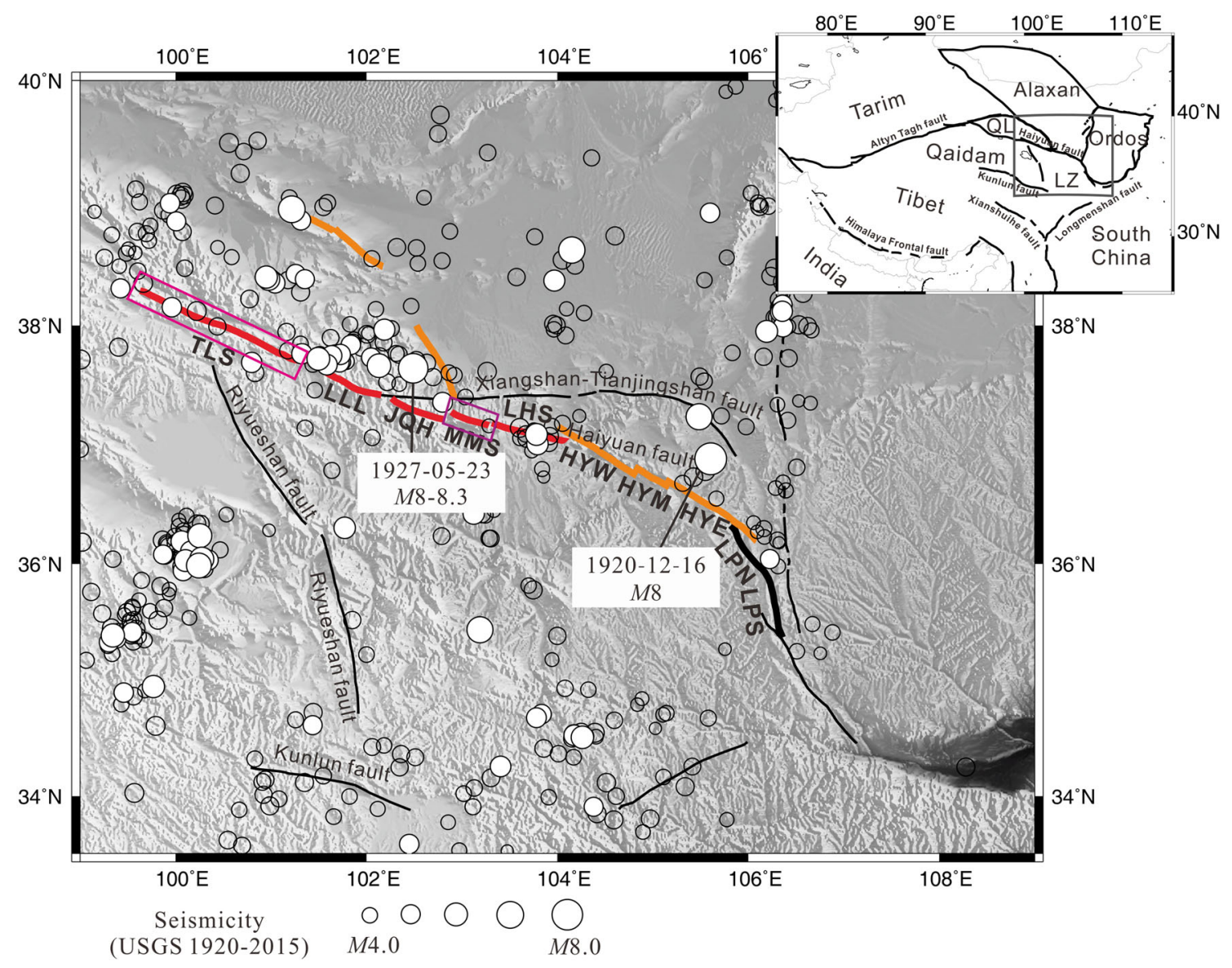

Fig. 1 Tectonic map of the northeastern Tibetan Plateau. The inset map on the upper right shows the study area and division of the blocks. Black circles represent earthquakes with magnitude equal to or less than 5.0 and white circles correspond to earthquakes with a magnitude greater than 5.0 during the period 1920-2015 (USGS). Orange lines represent surface ruptures of the $1920 M 8$ and $1927 M 8-8.3$ earthquakes, respectively. The red line follows the Tianzhu seismic gap (Gaudemer et al. 1995). Rectangles represent segments with high seismic hazard. TLS Tuolanshan, LLL Lenglongling, JQH Jinqianghe, MMS Maomaoshan, $L H S$ Laohushan, $H Y W$ Western Haiyan, HYM Middle Haiyuan, HYE Eastern Haiyuan, $L P N$ Northern Liupanshan, LPS Southern Liupanshan; $Q L$ Qilian block, LZ Lanzhou block

from each other and the largest differences are of an order of magnitude, the near-field deformation is relatively poorly constrained by previous Global Positioning System (GPS) data and block models seldom consider non-uniform internal strain. In addition, four historical earthquakes that occurred 3500-3900 years ago suggest an average recurrence interval of approximately 1000 years, corresponding to the time elapsed since the last major event (Liu-Zeng et al. 2007). Thus the Tianzhu gap is the most probable site for the next large rupture on the fault and an assessment of its seismic hazard is an important goal (Cavalié et al. 2008).

For this paper, we collected GPS data from Crustal Movement Observation Network of China (CMONOC I) and Continental Tectonic Environmental Monitoring Network of China (CMONOC II) from 1999-2014. Sixteen campaign-mode GPS stations in the near-field of the Haiyuan fault were established in 2013 and two of these were surveyed during 2013-2014. Moreover, 13 campaign-mode GPS stations from CMONOC were occupied two epochs in the period of 2013-2014 (Fig. 2). A denser velocity field in the northeastern Tibetan Plateau was derived. A rigid model, a uniform strain model and a linear strain model were applied to invert the deformation of the blocks. The fault slip rate, the locking depth, and the moment accumulation rate of each segment were sequentially inverted. Block deformation and its implication for tectonics in the northeastern Tibetan Plateau are discussed.

\section{Tectonic setting}

The present-day tectonic features of the $\sim 1000 \mathrm{~km}$ Haiyuan-Liupanshan fault are the result of geodynamic processes related to the India-Eurasian convergence some 


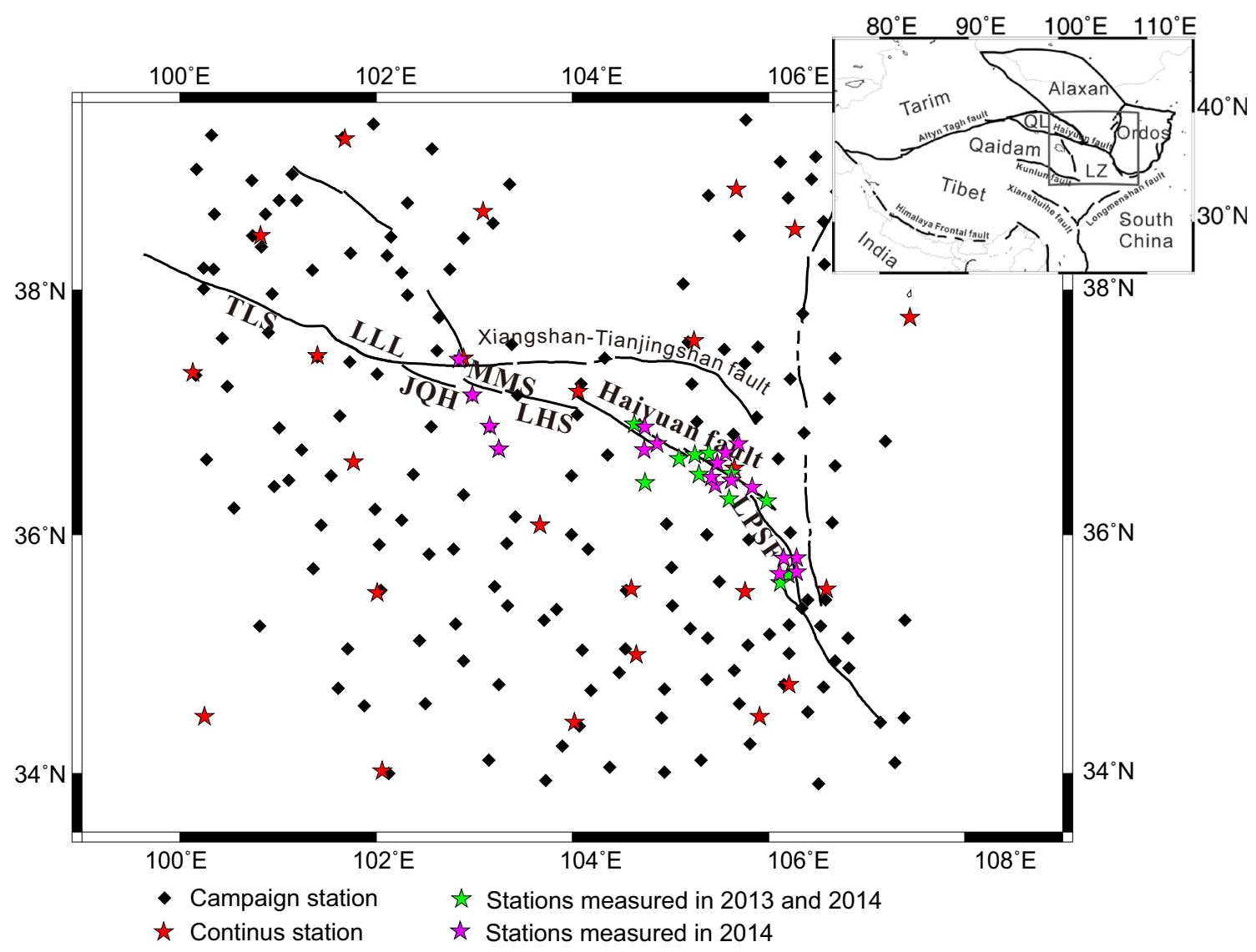

Fig. 2 A map showing the locations of the GPS stations around the northeastern margin of the Tibetan Plateau. The black squares are CMONOC campaign stations, and the red stars are the CMONOC continuous stations. The green stars are stations we established in 2013 and monitored in 2013 and 2014, and the pink stars are stations we monitored in 2014

50 Myr ago (Molnar and Tapponnier 1975; Tapponnier and Molnar 1977). The deformation of the Haiyuan fault is characterized by a left-lateral strike-slip movement (Gaudemer et al. 1995), while the Liupanshan fault is mainly thrusting ( $\mathrm{Li}$ et al. 2013). The left-lateral strike-slip on the Haiyuan fault has been transformed into crustal shortening and contraction in the eastern end along the Liupanshan (Zheng et al. 2013).

Two large shocks have ruptured the Haiyuan fault during the twentieth century: the $M 8$ Haiyuan earthquake in 1920 and the M8-8.3 Gulang thrust earthquake in 1927 (Zhang et al. 1987; Cavalié et al. 2008) (Fig. 1). Gaudemer et al. (1995) identified a $260 \mathrm{~km}$-long stretch of the fault extending between those two rupture zones as a seismic gap, designated as the Tianzhu gap, which can be divided into four segments (Liu-Zeng et al. 2007) from west to east; (1) the Lenglongling segment, (2) the Jinqianghe segment, (3) the Maomaoshan segment, and (4) the Laohushan segment. The western and eastern ends of the Haiyuan-Liupanshan fault are divided into the Tuolaishan segment, the Haiyuan segment (composed of the western, middle and eastern segments), and the Liupanshan segment (consisting of northern and southern segments) (Li et al. 2009). The Haiyuan segment is the segment ruptured during the 1920 event (Fig. 1).

The Holocene slip rate of the Haiyuan fault was estimated from offset measurements and the dating of morphological markers. The slip rate decreases from $19 \pm 5 \mathrm{~mm} / \mathrm{a}$ along the Lenglongling segment to $12 \pm 4 \mathrm{~mm} / \mathrm{a}$ along the Maomaoshan-Laohushan segments (Lasserre et al. 1999), to 3.5-6.5 mm/a along the Haiyuan segment $(4.5 \pm 1.1 \mathrm{~mm} / \mathrm{a}$ ( $\mathrm{Li}$ et al. 2009), $5-6.5 \mathrm{~mm} / \mathrm{a}$ (Tian et al. 2001), 4-6 mm/a (Zhang et al. 1991)). However, He et al. (2000) and Yuan et al. (1998) estimated the slip rate along the Lenglongling and Maomaoshan segment is only $4-5 \mathrm{~mm} / \mathrm{a}$. Slip rate estimates using block models based on GPS data suggest a $3.2-9 \mathrm{~mm} / \mathrm{a}$ strike-slip rate along the Haiyuan fault $(3.6-5.5 \mathrm{~mm} / \mathrm{a}$ ( $\mathrm{Li}$ et al. 2013), 4.6-4.7 mm/a (Loveless and Meade 2011), 7-9 mm/a (Meade 2007), 5-6 mm/a (Thatcher 2007), $3.4 \pm 0.2 \mathrm{~mm} /$ a (Wang et al. 2009)), while the slip rates derived from dislocation models tend to be smaller between 1.2 and 
$5.5 \mathrm{~mm} / \mathrm{a}$ [2-4.5 mm/a (Duvall and Clark 2010), 1.2-2.2 mm/a (Zhang et al. 2005), 1.4-4.8 mm/a (Ge et al. 2013), 2-5.5 mm/a (Zhang et al. 2011)]. Cavalié et al. (2008) obtained a $4.2-8 \mathrm{~mm} / \mathrm{a}$ slip rate by modeling the fault parallel velocity profile along the Maomaoshan-Laohushan segment using ERS InSAR data and inferred the presence of creep at a shallow depth. Additionally, the slip rate of the Liupanshan fault may be less than $1.7 \mathrm{~mm} / \mathrm{a}(\mathrm{Li}$ et al. 2013; Zhang et al. 2011). The cause for the discrepancy between the short term (i.e., geodetic) and the average long-term (i.e., Quaternary) slip rates remains controversial (Jolivet et al. 2012).

\section{Methodology}

\subsection{GPS measurement and data processing}

The principal data used for this study are from the Crustal Movement Observation Network of China (CMONOC I) and the Tectonic and Environmental Observation Network of Mainland China (CMONOC II) (Gan et al. 2012) and were collected during 1999 and 2014, including 24 continuous stations, and 161 campaign-mode stations with an occupation of seven epochs over the time spanning from 1999 to 2013. Moreover, we conducted observations at 11 stations (including two newly built (2013) stations and nine pre-existing CMONOC stations) in 2013 and 29 stations (including two newly built (2013) stations, 13 pre-existing CMONOC stations and 14 newly built stations) in 2014 across the Haiyuan fault (Fig. 2).

The GPS data were processed together with 20 IGS sites around China using GAMIT/GLOBK10.4 software (Herring et al. 2010; King and Bock 2010). We processed the data in four steps (Shen et al. 2001): (1) All the observational data for a given day were processed together with the data from 20 IGS stations to solve for the daily loosely constrained station coordinates and the satellite orbits, (2) the daily solution for the local stations was combined with loosely constrained global solutions produced at the Scripps Orbital and Position Analysis Center (SOPAC, http://sopac.ucsd.edu/) using GLOBK software. Time series for the site coordinates were derived. Daily solutions with errors more than $20 \mathrm{~mm}$ or three sigma were deleted after removing the linearization tendency, (3) the station positions and velocities were estimated in the ITRF2008 using the GLOBK software. We imposed a frame of reference by minimizing the position and velocity deviations of 34 globally distributed IGS tracking stations with respect to the ITRF2008 while estimating the orientation, translation, and scale transformation parameters, and (4) the velocity solution was transformed into a Eurasia-fixed frame of reference using the Euler vector for Eurasia with respect to the ITRF2008 (Altamimi et al. 2012) (Fig. 3).

\subsection{Model}

The northeastern Tibetan Plateau is divided into four blocks based on previous studies (Zhang et al. 2003; Wang et al. 2011), the Ordos block, the Alaxan block, the Qilian block and the Lanzhou block (Figs. 1, 2). The block boundaries coincide to the Haiyuan-Liupanshan fault.

The traditional theory of plate tectonics assumes that a block is a rigid body. The block kinematic can be described by the rigid model (RRM) (Li et al. 2004) using Euler's theorem:

$$
\left[\begin{array}{l}
V_{\mathrm{e}} \\
V_{\mathrm{n}}
\end{array}\right]=r\left[\begin{array}{lll}
-\sin \varphi \cos \lambda & -\sin \varphi \sin \lambda & \cos \varphi \\
\sin \lambda & -\cos \lambda & 0
\end{array}\right]\left[\begin{array}{l}
\omega_{x} \\
\omega_{y} \\
\omega_{z}
\end{array}\right],
$$

where $(\lambda, \varphi)$ are the longitude and latitude of a point within the block, $\left(V_{\mathrm{e}}, V_{\mathrm{n}}\right)$ are the eastern and northern components of the velocity vector, $r$ is the radius of the Earth, and $\left(\omega_{x}\right.$, $\left.\omega_{y}, \omega_{z}\right)$ is the Euler vector.

However, other studies (Li et al. 2001, 2004; Qu et al. 2014) have shown that blocks more closely resemble elastic or visco-elastic entities rather than purely rigid bodies. Deformation exists not only over the boundary zones of the blocks but also within the blocks. GPS velocities are a result of the combined effect of block rotation and internal deformation. If the deformation within a block is homogeneous, the velocity vector of a point within the block could be described using a uniform strain model (HSM) as follows:

$$
\begin{aligned}
{\left[\begin{array}{l}
V_{\mathrm{e}} \\
V_{\mathrm{n}}
\end{array}\right]=} & r\left[\begin{array}{lll}
-\sin \varphi \cos \lambda & -\sin \varphi \sin \lambda & \cos \varphi \\
\sin \lambda & -\cos \lambda & 0
\end{array}\right]\left[\begin{array}{l}
\omega_{x} \\
\omega_{y} \\
\omega_{z}
\end{array}\right] \\
& +\left[\begin{array}{ll}
\varepsilon_{\mathrm{e}} & \varepsilon_{\mathrm{en}} \\
\varepsilon_{\mathrm{ne}} & \varepsilon_{\mathrm{n}}
\end{array}\right]\left[\begin{array}{l}
x \\
y
\end{array}\right]
\end{aligned}
$$

where $\varepsilon_{\mathrm{e}}, \varepsilon_{\mathrm{en}}, \varepsilon_{\mathrm{ne}}, \varepsilon_{\mathrm{n}}$ are the parameters that describe the uniform strain within a block and $x=\cos \varphi\left(\lambda-\lambda_{0}\right)$ and $y=r\left(\varphi-\varphi_{0}\right),\left(\lambda_{0}, \varphi_{0}\right)$ are the longitude and latitude of the block's geometric center.

If strain is uneven within a block, the motion of a point within the block could be described by rigid rotation plus the non-uniform deformation of the block. The observed GPS velocity can be defined by a linear strain model (LSM) (Li et al. 2001) as shown below: 


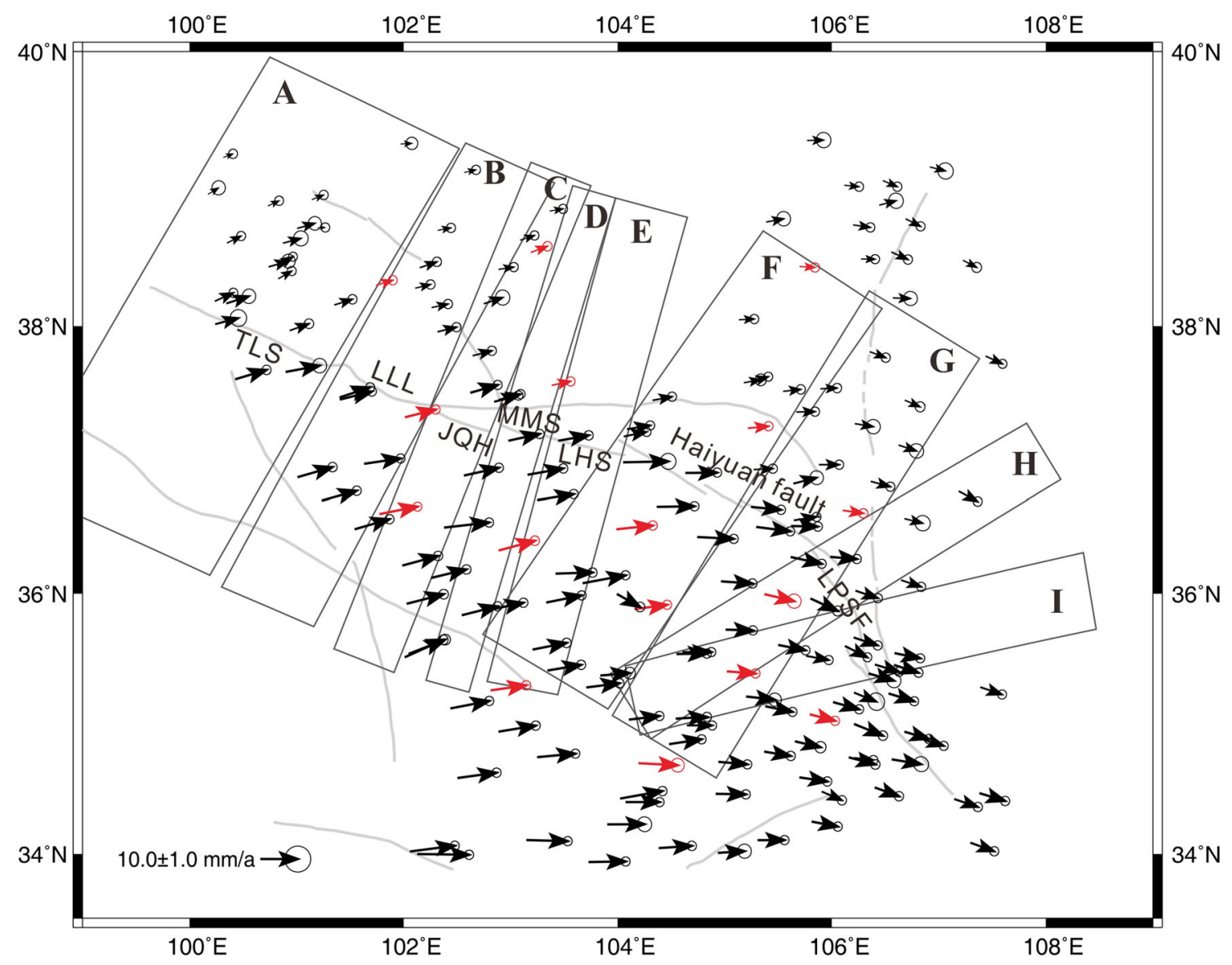

Fig. 3 GPS velocities with respect to the stable Eurasian plate. Error ellipses indicate the $95 \%$ confidence levels. Red arrows are sites used to define the self-fixed reference frame. Black rectangles indicate the velocity profiles for Fig. 5. A Tuolaishan segment, B Lenglongling segment, C Jinqianghe segment, D Maomaoshan segment, E Laohushan segment, F Haiyuan western and middle segment, G Haiyuan eastern segment, H Liupanshan northern segment, I Liupanshan southern segment

$$
\begin{aligned}
& {\left[\begin{array}{l}
V_{\mathrm{e}} \\
V_{\mathrm{n}}
\end{array}\right]=r\left[\begin{array}{ccc}
-\sin \varphi \cos \lambda & -\sin \varphi \sin \lambda & \cos \varphi \\
\sin \lambda & -\cos \lambda & 0
\end{array}\right]\left[\begin{array}{l}
\omega_{x} \\
\omega_{y} \\
\omega_{z}
\end{array}\right]} \\
& +\left[\begin{array}{cc}
\varepsilon_{\mathrm{e}} & \varepsilon_{\mathrm{en}} \\
\varepsilon_{\mathrm{ne}} & \varepsilon_{\mathrm{n}}
\end{array}\right]\left[\begin{array}{l}
x \\
y
\end{array}\right]+\left[\begin{array}{ll}
A_{0} & B_{0} \\
B_{0} & C_{0}
\end{array}\right]\left[\begin{array}{l}
x \\
y
\end{array}\right] \\
& +\frac{1}{2}\left[\begin{array}{ll}
A_{1} & B_{2} \\
B_{1} & C_{2}
\end{array}\right]\left[\begin{array}{l}
x^{2} \\
y^{2}
\end{array}\right]+\left[\begin{array}{l}
A_{2}+B_{1} \\
B_{2}+C_{1}
\end{array}\right] x y,
\end{aligned}
$$

where $A_{0}, A_{1}, A_{2}, B_{0}, B_{1}, B_{2}, C_{0}, C_{1}, C_{2}$ are the strain parameters.

According to statistical theory (Tao 2007), the unbiasedness and effectiveness of a model are parameters that can be used to evaluate which model is more suitable to delineate block deformation. We used $\Delta V$ and $S_{\Delta v}$ as the criteria for unbiasedness and optimization, respectively:

$$
\Delta V=\frac{1}{2 n}\left(\sum_{i=1}^{n} \Delta v_{\mathrm{e} i}+\sum_{i=1}^{n} \Delta v_{\mathrm{n} i}\right)
$$

$S_{\Delta v}=\sqrt{\frac{1}{2 n-R}\left[\sum_{i=1}^{n} \Delta v_{\mathrm{e} i}^{2}+\sum_{i=1}^{n} \Delta v_{\mathrm{n} i}^{2}\right]}$,

where $\Delta v_{\mathrm{e} i}$ and $\Delta v_{\mathrm{n} i}$ are the residual velocity components of a GPS point in the eastern and northern directions, $n$ is the number of GPS stations and $R$ is the number of undetermined parameters (Qu et al. 2014).

\section{Results and analyses}

\subsection{Characteristics of GPS velocity field}

The velocity field of the Tibetan Plateau relative to a stable Eurasia includes a rigid rotational component and an interior deformation component (Gan et al. 2007) (Fig. 3). In order to highlight the interior deformation of the northeastern Tibetan, we solved for the Euler vector of 16 GPS stations (Fig. 2) which are stable and evenly distributed within the region. The selection of well-behaved, 
evenly distributed, and stable stations follows criteria proposed by Rebischung et al. (2012) (Table 1). We also rejected sites with residuals beyond the 1.5 sigma [Eq. (1)]. The resulting Euler pole has a location and magnitude of $\left(61.46^{\circ} \pm 3.12^{\circ}, 99.19^{\circ} \pm 1.13^{\circ}, 0.156^{\circ} \pm 0.018^{\circ} / \mathrm{Ma}\right)$. Figure 4 shows the new velocity field after taking out the rigid rotation of the northeastern Tibetan Plateau. Velocities to the south of the Haiyuan-Liupanshan fault show a clockwise rotation, while velocities to the north of the fault zone exhibit a counter-clockwise rotation. The results demonstrate that the Haiyuan-Liupanshan fault is experiencing a left-lateral striking-slip movement with a compression component, which is in agreement with previous studies (Gan et al. 2007; Ge et al. 2013; Wang et al. 2011). Figure 4 also shows that the fault movement from the Tuolaishan segment to the Laohushan segment is strikeslip with a thrusting component, the Haiyuan segment has mainly left-lateral movement and the Liupanshan segment is dominated by thrusting.

Horizontal velocities show an obvious reduction from the south to the north (about $7.0 \mathrm{~mm} / \mathrm{a}$ in the south, decreasing to less than $2.0 \mathrm{~mm} / \mathrm{a}$ near the Haiyuan fault), demonstrating that the crustal strain is accumulating along this deformation zone. Velocities decrease significantly from the outside to the center of the Lanzhou block (Fig. 4), suggesting that an internal strain exists within the block. Velocities also change slightly within the Alaxan and the Qilian blocks, indicating that these blocks are deformable. However, whether an internal strain exists in the Ordos block could not be ascertained from the data in Fig. 4.

\subsection{Block deformation and fault slip rate}

We calculated $S_{\Delta v}$ and $\Delta V$ for the RRM, HSM, and LSM, respectively (Table 2 ). The results suggest that the deformation of the Alaxan and the Lanzhou blocks could be described using the HSM and that of the Qilian block using the LSM. However, it is difficult to choose a deformation model to invert the Ordos block between the HSM and the LSM. The applicability of the two models for a specific block can be distinguished with an F test (Qu et al. 2014). We carried out the F test and concluded that the LSM is more suitable for the Ordos block at a significance level of 0.05 .

The directions of the residuals shown in Fig. 5 are stochastic in every block for these three block models. Meanwhile, the residuals derived from the LSM are smaller than those from the HSM in the Ordos, the Alaxan and the Lanzhou blocks but larger in the Qilian block, and residuals derived from the RRM are the largest. As a result, it is reasonable to model the Ordos, the Alaxan, and the Lanzhou blocks with the LSM and the Qilian block with the HSM. The residuals histogram conforms to the Gaussian normal distribution, indicating that the models fit the GPS velocities well without systematic errors. It should be noted that the residuals around the block boundaries have a relatively larger magnitude due to the concentration of the crustal deformation (Thatcher 2007; Wang et al. 2011). In other words, strain from interseismic coupling on blockbounding faults has significant impact on sites in the nearfield, especially near block boundaries. Complicated crustal deformation around the blocks boundaries may be beyond the modeling of the current three block models.

The slip rate of each segment was estimated based on block models in terms of the relative movements of faults (Table 4). The RRM was defined as model $A$ in order to obtain slip rates that matched long-term geological results (Zhang et al. 2007). The LSM was used to model the Ordos, the Alaxan, and the Lanzhou blocks, and the HSM was used to delineate the Qilian block. We named the mixed latter as model B (Table 3). Fault parallel and normal slip rate profiles for every segment were also mapped (Fig. 6).

The slip rates in Table 4 show that the overall characteristic of the Haiyuan-Liupanshan fault is dominated by a left-lateral striking-slip movement with a compression component. The slip rates derived from model $A$ suggest
Table 1 Criteria used to select the northeastern Tibetan-fixed reference stations

The first eight criteria refer to the ITRF2008 results, the last one refer to the Eurasia-fixed results

\begin{tabular}{ll}
\hline Criterion & Threshold \\
\hline Data span & $>5$ years \\
Maximum time span between two discontinuities & $>2$ years \\
Number of discontinuities & $<2$ \\
Number of velocity discontinuities & $=0$ \\
3 D formal error of latest velocity estimate & $<0.3 \mathrm{~mm} / \mathrm{a}$ \\
Residual time series & $3 \mathrm{D} \mathrm{RMS}<5 \mathrm{~mm}$; visual inspection \\
Distance from fault & $>50 \mathrm{~km}$ \\
Distance between each other & $>100 \mathrm{~km}$ \\
Model residual & $<1.5 \mathrm{sigma} ;<0.5 \mathrm{~mm} / \mathrm{a}$
\end{tabular}




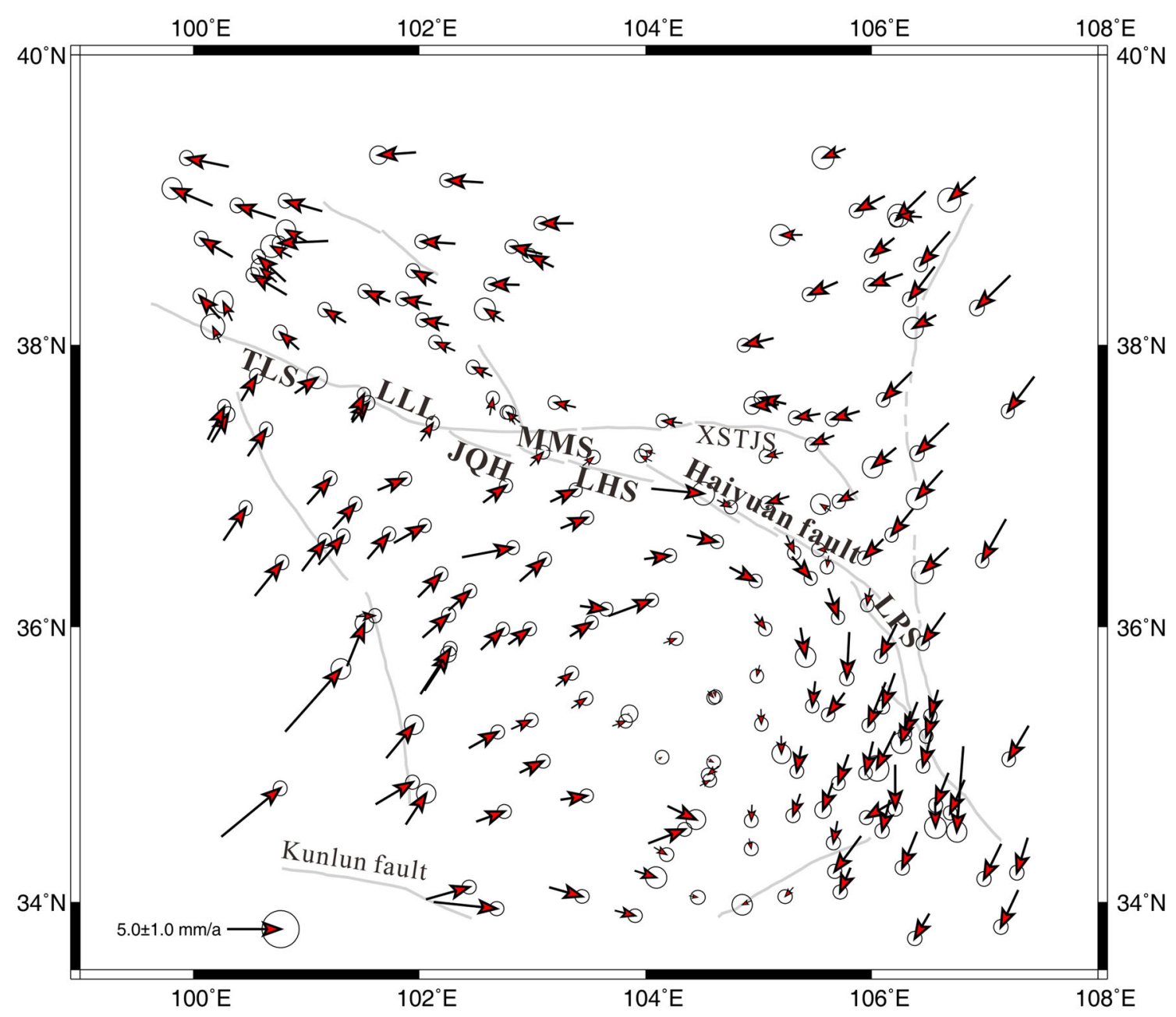

Fig. 4 GPS velocity field in a northeastern Tibetan Plateau fixed reference frame. The thick gray solid lines indicate active faults. The gray ellipse at the tip of each velocity vector is the $95 \%$ confidence level

Table 2 Statistics for models

\begin{tabular}{lllr}
\hline Block name & Model & $\mathrm{S}_{\Delta v}(\mathrm{~mm} / \mathrm{a})$ & $\Delta V(\mathrm{~mm} / \mathrm{a})$ \\
\hline Ordos & RRM & 0.6814 & 0.00378 \\
& HSM & 0.5726 & 0.00308 \\
\multirow{3}{*}{ Alaxan } & LSM & 0.5431 & 0.00312 \\
& RRM & 0.9499 & 0.00110 \\
& HSM & 0.6553 & 0.00095 \\
Qilian & LSM & 0.4894 & 0.00096 \\
& RRM & 0.8726 & 0.00223 \\
& HSM & 0.5337 & 0.00174 \\
Lanzhou & LSM & 0.5495 & 0.00178 \\
& RRM & 1.4065 & -0.00038 \\
& HSM & 1.0764 & -0.00025 \\
& LSM & 0.8895 & -0.00006 \\
\hline
\end{tabular}

that the fault activity decreases from the Tuolaishan segment to the southern Liupanshan segment with a reduction in the striking-slip rate from $\sim 4.8 \mathrm{~mm} / \mathrm{a}$ to $0.3 \mathrm{~mm} / \mathrm{a}$ and in the shorting rate from $\sim 3 \mathrm{~mm} / \mathrm{a}$ to $0.7 \mathrm{~mm} / \mathrm{a}$. There is an increase in the compression component along the Liupanshan segment due to the transformation of the displacement between Haiyuan and Liupanshan (Zheng et al. 2013). Estimated slip rates from profiles (Table 4; Fig. 6) across the fault are consistent with model $A$. Results from model $B$ exhibit similar trends to those from model $A$, with a smaller magnitude. Studies (Zhang et al. 2007; Wei et al. 2012) suggest that the slip rate obtained from the RRM and the velocity profiles probably reflects the far-field deformation of the fault, and yet the slip rate derived from the HSM and the LSM reflects the near-field crustal deformation of the fault. 


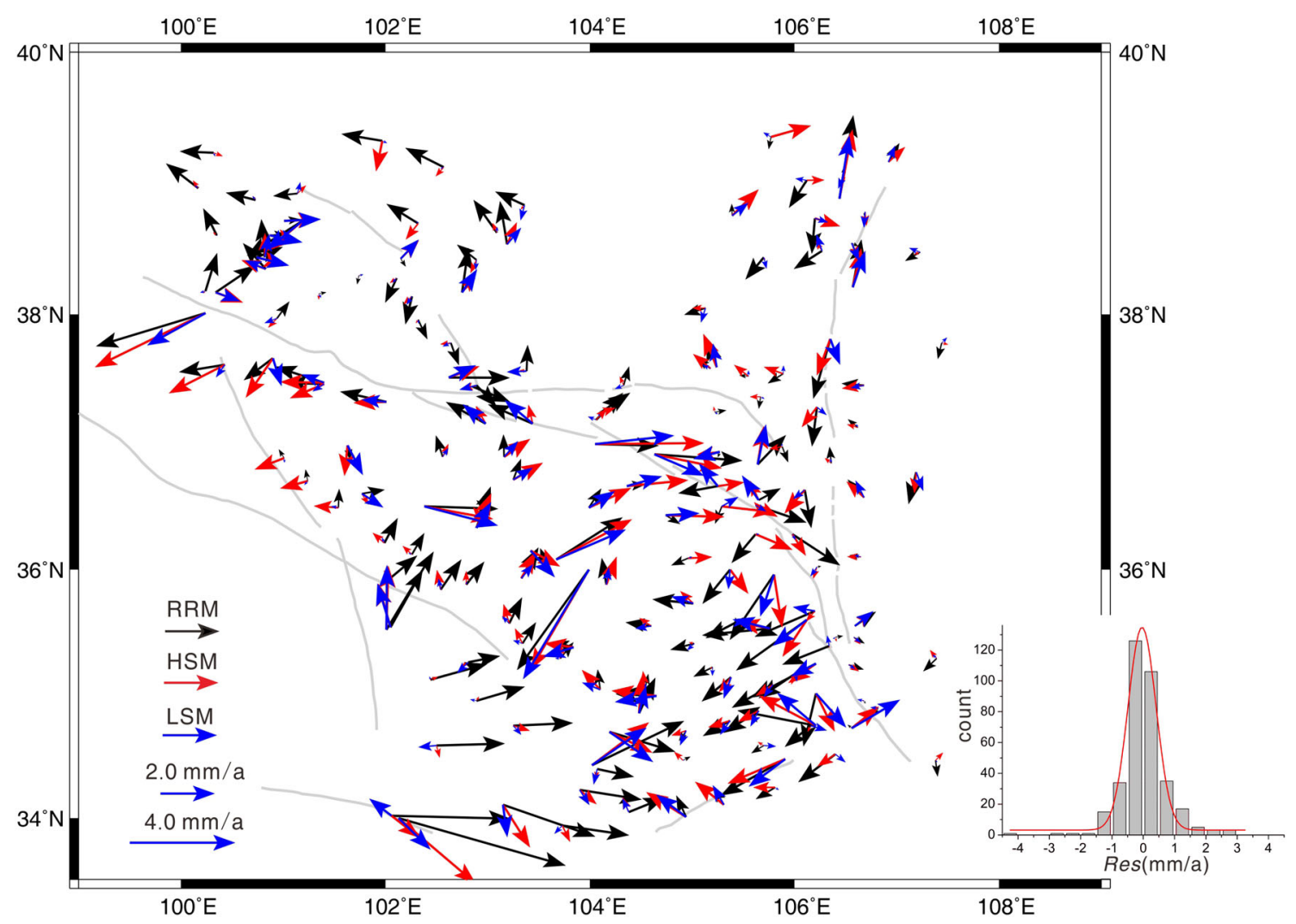

Fig. 5 Residuals of the GPS velocities and its histogram. The histogram consists of residuals derived from LSM within the Ordos, the Alaxan, and the Lanzhou block, and from HSM within the Qilian block

Table 3 Model description

\begin{tabular}{|c|c|c|c|c|c|c|c|c|}
\hline Model & $A$ & & & & $B$ & & & \\
\hline Block & Ordos & Alaxan & Lanzhou & Qilian & Ordos & Alaxan & Lanzhou & Qilian \\
\hline Deformation pattern & RRM & & & & LSM & & & HSM \\
\hline
\end{tabular}

Velocity gradients across the Haiyuan segment (Fig. 6a, $\mathrm{f}, \mathrm{g}$ ) indicate that the fault has a shallow locking depth and may still suffer from the impact of the 1920 M8.0 earthquake (Li et al. 2013; Meade and Hager 2005; Savage and Prescott 1978). Velocity gradients are also found on the western side of the Liupanshan segment (Fig. 6b, h, i). The compression component decreases from far-field $(100-200 \mathrm{~km})$ to near-field of the fault $(50-10 \mathrm{~km})$ with a slip rate from $\sim 8 \mathrm{~mm} / \mathrm{a}$ to $\sim 6 \mathrm{~mm} / \mathrm{a}$, demonstrating that the left-lateral strike-slip on the Haiyuan fault is transforming into a thrusting component of the Liupanshan fault and crustal shortening in the region. The relative movement (Fig. 6b, h, i) is very small between the two sides $(<50 \mathrm{~km})$ of the Liupanshan segment, suggesting that strain might have accumulated in this area.

Our preferred slip rate for the Haiyuan fault derived from model $B$ (from the Tuolaishan segment to the
Haiyuan eastern segment) is about $2.0-3.2 \mathrm{~mm} / \mathrm{a}$, which is consistent with the estimate of $\mathrm{Ge}$ et al. (2013) of 1.4-3.5 mm/a. Using a finite method, Zhang et al. (2011) modeled GPS velocities in the northeastern Tibetan Plateau and obtained a value for the strike-slip of the Haiyuan fault of $2-5.5 \mathrm{~mm} / \mathrm{a}$. A similar slip rate of $2-4.5 \mathrm{~mm} / \mathrm{a}$ was obtained by analyzing GPS velocities and the Quaternary fault slip of the main faults in northeastern Tibet (Duvall and Clark 2010). Moreover, the inversion of the 1683 GPS velocities within 31 blocks based on a block model by Wang et al. (2009) revealed that the strike-slip rate of the Haiyuan fault is $3.0-3.4 \mathrm{~mm} / \mathrm{a}$. Those slip rates correspond well with our results. Moreover, the slip rate of the Liupanshan fault is similar to that found in previous studies ( $\sim 1.0 \mathrm{~mm} / \mathrm{a})$ (Zhang et al. 2011; Li et al. 2013), but with a smaller fault normal component. Discrepancies may arise from different models and datasets. 

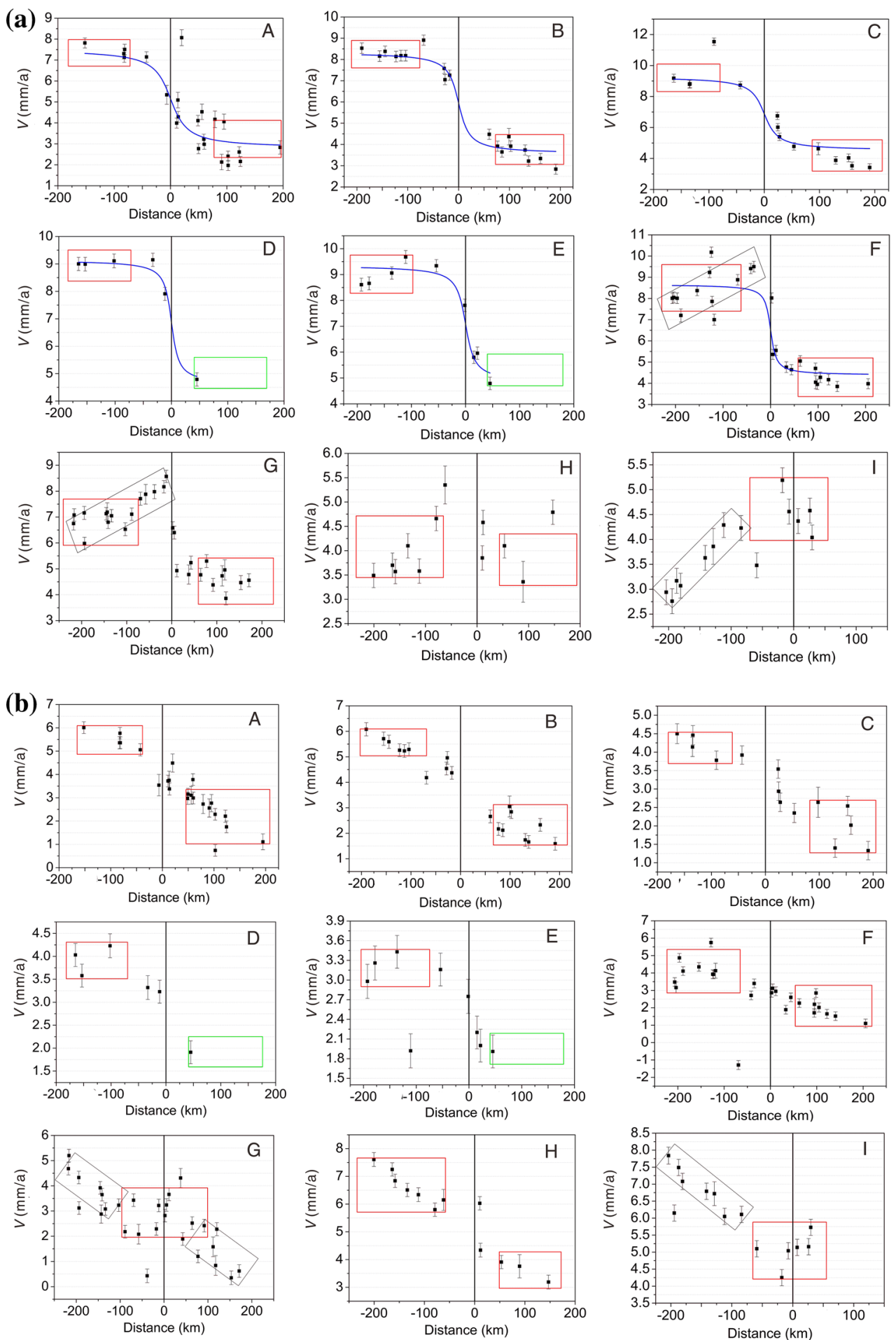

Fig. 6 Profiles along the fault (a) and perpendicular to the fault (b). Blue arc tangent curves are fitted velocity profiles. Red and green rectangles are used to estimate relative movement across faults and black rectangles are used to describe velocities tendency. a Tuolaishan segment, b Lenglongling segment, c Jinqianghe segment, d Maomaoshan segment, e Laohushan segment, f Haiyuan western and middle segment, g Haiyuan eastern segment, h Liupanshan northern segment, i Liupanshan southern segment 
Table 4 Fault slip rate and locking depth (positive is left-lateral and compression)

\begin{tabular}{|c|c|c|c|c|c|c|c|c|c|}
\hline \multirow[t]{2}{*}{ Fault } & \multicolumn{3}{|c|}{ Fault parallel (mm/a) } & \multicolumn{3}{|c|}{ Fault normal (mm/a) } & \multirow{2}{*}{$\begin{array}{l}\text { Locking } \\
\text { depth }(\mathrm{km})\end{array}$} & \multirow{2}{*}{$\begin{array}{l}\text { Moment accumulation rate } \\
\left(10^{14} \mathrm{Nm} / 100 \mathrm{a} \mathrm{km}\right)\end{array}$} & \multirow{2}{*}{$\begin{array}{l}\text { Slip rate } \\
(\mathrm{mm} / \mathrm{a})\end{array}$} \\
\hline & Model $A$ & Model $B$ & Profile & Model $A$ & Model $B$ & Profile & & & \\
\hline TLS & $4.76 \pm 0.08$ & $2.65 \pm 0.19$ & 4.3 & $2.97 \pm 0.08$ & $1.11 \pm 0.19$ & 3.2 & 21.8 & 1.87 & $2.87 \pm 0.27$ \\
\hline LLL & $4.79 \pm 0.08$ & $2.63 \pm 0.16$ & 4.6 & $1.84 \pm 0.07$ & $0.76 \pm 0.16$ & 3.0 & 15.2 & 1.24 & $2.74 \pm 0.23$ \\
\hline $\mathrm{JQH}$ & $4.79 \pm 0.09$ & $2.23 \pm 0.15$ & 4.4 & $0.01 \pm 0.09$ & $0.10 \pm 0.16$ & 2.2 & 17.6 & 1.18 & $2.23 \pm 0.22$ \\
\hline MMS & $4.54 \pm 0.06$ & $2.34 \pm 0.24$ & 4.5 & $1.69 \pm 0.07$ & $0.46 \pm 0.26$ & 2.0 & 19.8 & 1.41 & $2.38 \pm 0.35$ \\
\hline LHS & $4.54 \pm 0.06$ & $2.54 \pm 0.18$ & 4.3 & $1.13 \pm 0.06$ & $0.36 \pm 0.19$ & 1.2 & 12.1 & 0.93 & $2.57 \pm 0.26$ \\
\hline HYW & $4.30 \pm 0.06$ & $2.70 \pm 0.14$ & 4.2 & $1.22 \pm 0.06$ & $0.71 \pm 0.14$ & 1.7 & 8.2 & 0.68 & $2.79 \pm 0.20$ \\
\hline HYM & $4.28 \pm 0.06$ & $2.54 \pm 0.13$ & & $0.67 \pm 0.06$ & $1.16 \pm 0.13$ & & & 0.69 & $2.79 \pm 0.18$ \\
\hline HYE & $4.11 \pm 0.07$ & $2.25 \pm 0.16$ & 3.5 & $0.73 \pm 0.07$ & $1.13 \pm 0.16$ & 1.0 & 7.1 & 0.54 & $2.52 \pm 0.23$ \\
\hline LPN & $0.62 \pm 0.07$ & $1.42 \pm 0.84$ & 0.5 & $3.27 \pm 0.07$ & $0.28 \pm 0.27$ & 3.4 & - & - & $1.45 \pm 0.88$ \\
\hline LPS & $0.32 \pm 0.07$ & $0.82 \pm 0.19$ & 0.4 & $2.69 \pm 0.07$ & $0.32 \pm 0.19$ & 1.8 & - & - & $0.88 \pm 0.27$ \\
\hline
\end{tabular}

4.3 Locking depth and moment accumulation rate of faults

A rough estimate of relative motion of the plate across a section where the fault is locked can be obtained from a dislocation model (Savage and Burford 1973):

$v=\left(\frac{b}{\pi}\right) \operatorname{actan}\left(\frac{x}{D}\right)$

where $D$ is the locking depth, $b$ is the long-term slip rate of the fault, $v$ is fault parallel velocity, and $x$ is the distance to the fault.

The fault locking depth was estimated by a least-squares fit of the fault parallel velocities (Table 2). The locking depth in the Liupanshan segment (northern and southern Liupanshan) is none for the model and is not suitable for low-angle faults (Fig. 6a, h, i). The overall characteristic of locking depth from the Tuolaishan segment to the Haiyuan eastern segment is a decrease from 21.8 to $7.1 \mathrm{~km}$, which is consistent with the decreasing trend for crustal thickness along the fault from west to east (Cui et al. 2009a, b). Cui et al. (2009a, b) gave a locking depth of 22.2 and $11.4 \mathrm{~km}$ for the Maomaoshan and the Laohushan segments, respectively, and $3.6-8.5 \mathrm{~km}$ for the Haiyuan segment based on the Smith-3D dislocation model. A locking depth of $15 \mathrm{~km}$ for the Jinqianghe segment is preferred by $\mathrm{Li}$ et al. (2013) based on GPS inversion. Our result for the locking depth is consistent with those studies. Moreover, the focal depth of the 1990 Tianzhu-Jingtai $M 6.2$ earthquake (the largest in decades) (Fig. 1) that occurred on the Maomaoshan is $12 \mathrm{~km}$, which matches our locking depth well. The focal depth of the 1920 Haiyuan $M 8$ earthquake is generally believed to be between 17 and $20 \mathrm{~km}$, which is different from our fitting locking depth for the Haiyuan segment. We speculate that the lower crust of the Haiyuan segment was not fully stuck until now, which may be the reason that no earthquakes with magnitude greater than 6.0 have occurred here during the past 95 years.

The seismic moment accumulation rate per unit length of the fault was also calculated. The moment accumulation rate $M$ depends on the fault length $l$, the locking depth $d_{j}$, the slip rate $v_{j}$, and the rock shear modulus $\mu$ :

$\frac{M_{j}}{l}=\mu d_{j} v_{j}$

An estimated locking depth was used to calculate the seismic moment accumulation rate per unit length for each segment (Table 4). As expected, the rate of moment accumulation is positively correlated with the locking depth. Those rates can be compared with the stress accumulation rate and the recurrence interval to establish the seismic hazard (Smith and Sandwell 2003). Fault segments that have a high seismic moment accumulation rate are associated with deep locking depths, while faults that have a shallow locking depth have a lower seismic moment accumulation rate and a correspondingly reduced hazard potential (Burgmann 2000). Regarding our understanding of earthquakes, all of the strain that builds up on the fault in the period between earthquakes must be released solely during large earthquakes. Tight fault coupling, high seismic moment accumulation rate, and the paucity of large seismic events over previous decades along the Tuolaishan segment and the Maomaoshan segment may imply more strain accumulation. Considering that the Tianzhu seismic gap corresponding to the time elapsed since the last major event (Liu-Zeng et al. 2007), we infer that a greater possibility of nucleation for a future event on the Tuolaishan segment and the Maomaoshan segment (lying along the Tianzhu seismic gap) exists. It should be emphasized that a complete scientific knowledge of the structure, palaeoseismic history, and dynamics of one fault are needed to our sense of security in terms of its seismic hazard (Zhang 2013). 


\section{Discussion}

\subsection{Characteristics of block deformation}

GPS measurements that uniquely quantify the present-day deformation of the Tibetan Plateau can be simply and usefully described by the relative motions of the active blocks and the fault slip across the block boundaries (Meade and Hager 2005; Thatcher 2007). Our results show that the block models fit the horizontal GPS velocities well for the northeastern Tibetan Plateau. The Lanzhou block and the Qilian block can be best described by the LSM and the HSM, respectively. The Qilian block is smaller in size and has fewer secondary faults within the block than the Lanzhou block, and it deforms more uniformly. Qu et al. (2014) used regional plate kinematic models to fit GPS data in the Fenwei basin and suggested that the Ordos block deforms rigidly. On the basis of 1350 GPS velocities, Zhang et al. (2005) inferred that the Ordos block behaved as a coherent block similar to the oceanic rigid block without internal deformation. Wang et al. (2011) came to a similar conclusion for the Ordos block. In addition, Wang et al. (2009) asserted that the Ordos block and the Alaxan block are obviously rigid and the strength of these blocks is comparable to that of the lithospheric plate. However, our preferred models for the Ordos block (LSM) and the Alaxan block (LSM) are different from those in these studies because our GPS sites within the Ordos and the Alaxan blocks are primarily distributed around the block boundaries where complicated crustal deformation is concentrated (Thatcher 2007; Wang et al. 2011).

Although the relative motion located at or near the block boundaries agrees to the expectations based on the structural mapping of the active faults, the predicted slip rates are generally considerably less than those obtained by geological methods. Moreover, we should keep a rigorous attitude that these three models maybe improved more in mathematical sense than crustal block deformation.

\subsection{Implication for tectonic deformation}

Two alternative end-number models were proposed to describe the tectonic deformation occurring in the Tibetan and elsewhere on the continent: continuum versus block models (England and Mckenzie 1982; Avouac and Tapponnier 1993). The key divergence of the two models is whether the deformation is distributed broadly or localized on a few major faults (England and Molnar 2005). Kinematic analysis of the Haiyuan fault provides some clues. Although velocities fit block models well, attention should be paid that the low slip rates estimated by the space geodetic methods along the Haiyuan-Liupanshan fault imply that continuum models should be preferred for the northeastern Tibetan Plateau, but this is still controversial (Thatcher 2007; Cavalié et al. 2008). Zhang et at. (2005) argued that the present-day tectonic deformation of Chinese mainland can be described in terms of a coupling model of rigid block movement and continuous deformation. Meanwhile, same set of GPS data could be fitted well by microplate model (Thatcher 2007) and visco-elastic model (Cao et al. 2009). A compromise is that both the GPS data and the low fault slip rates implied are quite compatible with the block motions in the northeastern Tibetan Plateau (Zhang et al. 2005; Thatcher 2007).

\section{Conclusions}

On the basis of the measurements made from 185 GPS stations around the northeastern margin of the Tibetan Plateau since 1999, we derived a new velocity field, which plays a more important role in constraining the near-field crustal deformation of the Haiyuan-Liupanshan fault. After removing the rigid rotation of the northeastern Tibetan Plateau, interior deformation demonstrates quite different features bounded by the Haiyuan-Liupanshan fault. Clockwise rotation at the southern side of the fault and counter-clockwise at the northern side as indicated by the GPS velocities suggest that the Haiyuan-Liupanshan fault is undergoing a left-lateral striking-slip movement with a compression component. Block models used to invert the present-day deformation of the northeastern Tibetan Plateau show that active deformation in this region can be explained by crustal block rotation with an internal strain. The slip rates inferred from the block models vary slightly along the Haiyuan fault $(2.0-3.2 \mathrm{~mm} / \mathrm{a})$ and the Liupanshan fault (0.9-1.5 mm/a), while the locking depth derived from the fault parallel velocities exhibit a large discrepancy along the Haiyuan fault $(7.1-21.8 \mathrm{~km})$. Compared to the adjacent area in the seismic gap, the Tuolaishan segment and the Maomaoshan segment with its high rate of moment accumulation coupled with the paucity of large earthquakes during the past $\sim 1000$ years constitute a high seismic risk in the future.

Acknowledgments We express our gratitude and thanks to all participants who helped to construct the network and take the GPS measurements. We are grateful to Guo Liming, Xu Xiaobo, Wang Jiaqing, Zuo Ronghu, Zhang Yingfeng and Jiang Yu for taking the GPS measurements in the summer of 2013 and 2014. We express our appreciation to three anonymous reviewers for their pertinent comments. Partial figures were generated with the GMT software (Wessel and Smith 1995). This study is supported by the National Natural Science Foundation of China (No. 41461164002, No. 41374015), the State Key Laboratory of Earthquake Dynamics (LED2013A02), and the Fundamental Research Funds for the Central Universities (R1401038A, 14CX02110A). 
Open Access This article is distributed under the terms of the Creative Commons Attribution 4.0 International License (http://crea tivecommons.org/licenses/by/4.0/), which permits unrestricted use, distribution, and reproduction in any medium, provided you give appropriate credit to the original author(s) and the source, provide a link to the Creative Commons license, and indicate if changes were made.

\section{References}

Altamimi Z, Métivier L, Collilieux X (2012) ITRF2008 plate motion model. J Geophys Res 117(B7):47-56

Avouac J, Tapponnier P (1993) Kinematic model of active deformation in central Asia. Geophys Res Lett 20(10):895-898

Burchfiel BC, Zhang PZ, Wang YP (1991) Geology of the Haiyuan fault zone, Ningxia-Hui autonomous Region, China, and its relation to the evolution of the northeastern margin of the Tibetan Plateau. Tectonics 10(6):1091-1110. doi:10.1029/ 92TC00001

Burgmann R (2000) Earthquake potential along the northern Hayward fault, California. Science 289(5482):1178-1182

Cao JL, Shi YL, Zhang H, Wang H (2009) Numerical simulation of GPS observed clockwise rotation around the eastern Himalayan syntax in the Tibetan Plateau. Chin Sci Bull 54(8):1398-1410

Cavalié O, Lasserre C, Doin MP, Peltzer G, Sun J, Xu X, Shen ZK (2008) Measurement of interseismic strain across the Haiyuan fault (Gansu, China), by InSAR. Earth Planet Sci Lett 275(3-4):246-257

Cui DX, Hu YX, Wang WP, Zhu GZ (2009a) Coulomb stress accumulation along Haiyuan fault zone. J Earth Sci 34(4): $641-650$

Cui DX, Wang QL, Hu YX, Zhu GZ (2009b) Inversion of GPS data for slip rates and locking depths of the Haiyuan fault. Acta Seismol Sin 31(5):516-525

Duvall AR, Clark MK (2010) Dissipation of fast strike-slip faulting within and beyond northeastern Tibet. Geology 38(3):223-226

England P, Mckenzie D (1982) A thin viscous sheet model for continental deformation. Geophys J R Astron Soc 70(2):295-321

England P, Molnar P (2005) Late Quaternary to decadal velocity fields in Asia. J Geophys Res 110(B12):501-509

Gan W, Zhang P, Shen Z, Niu Z, Wang M, Wan Y, Zhou D, Cheng J (2007) Present-day crustal motion within the Tibetan plateau inferred from GPS measurements. J Geophys Res 112(B8): 582-596

Gan W, Li Q, Zhang R, Shi HB (2012) Construction and application of tectonics and environmental observation network of mainland China. J Eng Stud 4:324-331. (in Chinese with English abstract)

Gaudemer Y, Tapponnier P, Meyer B, Peltzer G, Guo S, Chen Z (1995) Partitioning of crustal slip between linked, active faults in the eastern Qilianshan, and evidence for a major seismic gap, the 'Tianzhu gap', on the western Haiyuan fault, Gansu (China). Geophys J Int 120(3):599-645

Ge WP, Wang M, Shen ZK, Yuan DY, Zheng WJ (2013) Interseismic kinematics and deformation patterns on the upper crust of Qaidam-Qilianshan block. Chin J Geophys 56:2994-3010

He WG, Liu BH, Yuan DY, Yang M (2000) Research on slip rates of the LengLongLing active fault zone. Northwest Seismol J 22(1):90-97

Herring T, King R, McClusky S (2010) GAMIT reference manual, release 10.4. Massachusetts Institute of Technology, Cambridge

Jolivet R, Lasserre C, Doin MP, Guillaso S, Peltzer G, Dailu R, Sun J, Shen ZK, Xu X (2012) Shallow creep on the Haiyuan fault (Gansu, China) revealed by SAR interferometry. J Geophys Res 117(B6):137-147
Jolivet R, Lasserre C, Doin MP, Peltzer G, Avouac JP, Sun J, Dailu R (2013) Spatio-temporal evolution of aseismic slip along the Haiyuan fault, China: implications for fault frictional properties. Earth Planet Sci Lett 377-378(5):23-33

King RW, Bock Y (2010) Documentation for the GAMIT GPS analysis software, release 10.0. Massachusetts Institute of Technology, Cambridge

Lasserre C, Morel PH, Gaudemer Y (1999) Post glacial left slip-rate and past occurrence of $M>8$ earthquakes on western Haiyuan fault, Gansu, China. J Geophys Res 104(B8):17633-17651. doi:10.1029/1998JB900082. (in Chinese with English abstract)

Li YX, Huang C, Hu XK, Shuai P, Hu XG, Zhang ZF (2001) The rigid and elastic-plastic model of the blocks in intro-plate and strain status of principal blocks in the continent of China. Acta Seismol Sin 23(6):565-572

Li YX, Li Z, Zhang JH, Huang C, Zhu WY, Wang M, Guo LQ, Zhang ZF, Yang GH (2004) Horizontal strain field in the Chinese mainland and its surrounding areas. Chin $J$ Geophys 47(2):222-231. (in Chinese with English abstract)

Li Q, Jiang ZS, Wu YQ, Zhao J, Wei WX, Liu XX (2013) Present-day tectonic deformation characteristics of Haiyuan-Liupanshan fault zone. J Geodesy Geodyn 33(2):18-22

Li C, Zhang P, Yin J, Min W (2009) Late quaternary left-lateral slip rate of the Haiyuan fault, northeastern margin of the Tibetan Plateau. Tectonics 28(5):357-369

Liu-Zeng J, Klinger Y, Xu X, Lasserre C, Chen G, Chen W, Chen WB, Tapponnier P, Zhang B (2007) Millennial recurrence of large earthquakes on the Haiyuan fault near Songshan, Gansu Province, China. Bull Seismol Soc Am 97(1B):14-34

Loveless JP, Meade BJ (2011) Partitioning of localized and diffuse deformation in the Tibetan Plateau from joint inversions of geologic and geodetic observations. Earth Planet Sci Lett 303(1-2):11-24. doi:10.1016/j.epsl.2010.12.014

Meade BJ (2007) Present-day kinematics at the India-Asia collision zone. Geology 35(1):81

Meade BJ, Hager BH (2005) Block models of crustal motion in southern California constrained by GPS measurements. J Geophys Res 110(B3):353

Molnar P, Tapponnier P (1975) Cenozoic tectonics of Asia: effects of a continental collision. Science 189(4201):419-426

Qu W, Lu Z, Zhang Q, Li ZH, Peng JB, Wang QL, Drummond Jane, Zhang M (2014) Kinematic model of crustal deformation of Fenwei basin, China based on GPS observations. J Geodyn 75(4):1-8

Rebischung P, Griffiths J, Ray J, Schmid R, Collilieux X, Garayt B (2012) IGS08: the IGS realization of ITRF2008. GPS Solut 16(4):483-494

Savage JC, Burford RO (1973) Geodetic determination of relative plate motion in central California. J Geophys Res 78(5):832-845

Savage JC, Prescott WH (1978) Asthenosphere readjustment and the earthquake cycle. J Geophys Res 83(B7):3369-3376

Shen ZK, Wang M, Li Y, Jackson DD, Yin A, Dong DN, Fang P (2001) Crustal deformation along the Altyn Tagh fault system, western China, from GPS. J Geophys Res 106(B12):30607-30621

Smith B, Sandwell D (2003) Coulomb stress accumulation along the San Andreas fault system. J Geophys Res 108(B6):2296

Tao BZ (2007) The statistical theory and methods of the survey measurement data processing. Surveying and Mapping Press, Beijing (in Chinese)

Tapponnier P, Molnar P (1977) Active faulting and tectonics in China. J Geophys Res 82(20):2905-2930

Thatcher W (2007) Microplate model for the present-day deformation of Tibet. J Geophys Res 112(B1):534-535

Tian QJ, Ding GY, Shen XH (2001) Pull-apart basins and the total lateral displacement along the Haiyuan fault zone in Cenozoic. Earthq Res China 17(2):167-175 
Wang W, Yang S, Wang Q (2009) Crustal block rotations in Chinese mainland revealed by GPS measurements. Earthq Sci 22(6): 639-649

Wang H, Liu M, Cao J, Shen X, Zhang G (2011) Slip rates and seismic moment deficits on major active faults in mainland China. J Geophys Res 116(B2):1161-1172

Wei W, Jiang ZS, Zhao J (2012) Motion characteristics of major faults in east boundary of Sichuan-Yunnan block obtained with GPS data. Geomat Inf Sci Wuhan Univ 37(9):1041-1044

Wessel P, Smith WHF (1995) New version of the generic mapping tools. EOS Trans Am Geophys Union 76(33):329

Yuan DY, Liu BH, Lu TY, He WG, Liu XF, Gan WJ (1998) Study on the segmentation in east segment of the northern Qilianshan fault zone. Northwest Seismol J 20(4):27-34

Zhang PZ (2013) Beware of slowly slipping faults. Nat Geosci 6(5):323-324

Zhang PZ, Burchfiel BC, Molnar P, Zhang WQ, Jiao DC, Deng QD, Wang YP, Leigh Royden, Song FM (1991) Amount and style of late Cenozoic deformation in the Liupan Shan area, Ningxia autonomous region, China. Tectonics 10(6):1111-1129

Zhang WQ, Jiao DC, Zhang PZ, Peter M, Burchfield BC, Deng QD, Wang YP, Song FM (1987) Displacement along the Haiyuan fault associated with the great 1920 Haiyuan, China, earthquake. Bull Seismol Soc Am 77(1):117-131

Zhang PZ, Deng QD, Zhang GM, Ma J, Gan WJ, Min W, Mao FY, Wang Q (2003) Active tectonic blocks and strong earthquakes in the continent of China. Sci China Ser D 33:12-20

Zhang PZ, Gan WJ, Shen ZK, Wang M (2005) A coupling model of rigid-block movement and continuous deformation: patterns of the present-day deformation of China's continent and its vicinity. Acta Geol Sin 79(6):748-756

Zhang PZ, Molnar P, Xu X (2007) Late quaternary and present-day rates of slip along the Altyn Tagh fault, northern margin of the Tibetan Plateau. Tectonics 26(5):1-8

Zhang XL, Shi ZM, Jiang FY, Zhu LY, Wang X (2011) Research on late tectonic deformation evolvement of Huaiyuan-Liupanshan arc fault and its surrounding area. J Geodesy Geodyn 31:20-24

Zheng WJ, Zhang PZ, He WG, Yuan DY, Shao YX, Zheng DW, Ge WP, Min W (2013) Transformation of displacement between strike-slip and crustal shortening in the northern margin of the Tibetan Plateau: evidence from decadal GPS measurements and late Quaternary slip rates on faults. Tectonophysics 584:267-280 